\title{
Sofrimento de trabalhadores da atenção básica em um contexto de tragédia: estratégias para evitar o adoecimento
}

\author{
Suffering of basic attention workers in a tragedy context: strategies to avoid advocacy
}

Sufrimiento de trabajadores de la atención básica en un contexto de tragedia: estrategias para evitar la adoecimiento

Cássia Cilene Saldanha da Silveira ${ }^{1 *}$, Daiany Saldanha da Silveira Donaduzzi², Fernanda Almeida Fettermann ${ }^{3}$, Andrieli Berger da Rosa ${ }^{1}$, Juliana Silveira Bordignon ${ }^{4}$, Marcelo Nunes da Silva Fernandes $^{5}$, Vânia Maria Fighera Olivo ${ }^{1}$.

\section{RESUMO}

Objetivo: analisar as vivências de sofrimento dos trabalhadores de equipes de atenção básica e as estratégias utilizadas no desempenho de suas ações para evitar o adoecimento em um contexto de tragédia. Métodos: Estudo exploratório-descritivo, com abordagem qualitativa. A coleta de dados ocorreu nos meses de julho e agosto de 2013, por meio de entrevista semiestruturada, realizada como trabalhadores da saúde. Os dados foram analisados por meio da Análise de Conteúdo. Resultados: Foi possível constatar a existência de sofrimento diante de uma situação ocorrida de forma abrupta e desestabilizadora que favorece o sofrimento, na qual os trabalhadores encontravam-se expostos aos riscos de adoecimento. Conclusão: Percebeu-se a necessidade do suporte organizacional, com ações e políticas de gestão que possam construir processos favoráveis à saúde do trabalhador. Destaca-se que apesar dos sofrimentos advindos do contexto da tragédia, os trabalhadores referem um fortalecimento subjetivo, com aquisição de um novo olhar diante da vida.

Palavras-chave: Atenção Primária à Saúde, Saúde do Trabalhador, Reconstrução Pós-desastre.

\begin{abstract}
Objective: to analyze the experiences of suffering of the workers of basic attention teams and the strategies used in the performance of their actions to avoid the illness in a context of tragedy. Methods: Exploratorydescriptive study, with qualitative approach. The data collection occurred in the months of July and August of 2013, through a semi-structured interview, performed as health workers. Data were analyzed through Content Analysis. Results: It was possible to verify the existence of suffering in the face of an abrupt and destabilizing situation that favors suffering, in which workers were exposed to the risks of illness. Conclusion: We noticed the need for organizational support, with actions and management policies that can build processes favorable to workers' health. It is noteworthy that despite the sufferings arising from the context of the tragedy, workers refer to a subjective strengthening, with the acquisition of a new look at life.
\end{abstract}

Key words: Primary Health Care, Worker's health, Post Disaster Reconstruction.

\footnotetext{
${ }^{1}$ Universidade Federal de Santa Maria (UFSM). Santa Maria-RS. *E-mail: cassia.ssb@hotmail.com

${ }^{2}$ Faculdade Integrada de Santa Maria (FISMA). Santa Maria-RS.

${ }^{3}$ Universidade Federal do Rio Grande do Sul. Santa Maria-RS.

${ }^{4}$ Prefeitura Municipal de Itajaí. Santa Maria-RS.

${ }^{5}$ Prefeitura Municipal de Santa Maroa. Santa Maria-RS.
}

SUBMETIDO EM: 7/2019

ACEITO EM: 8/2019

PUBLICADO EM: 9/2019

REAS/EJCH | Vol.11(15) | e1296 | DOI: https://doi.org/10.25248/reas.e1296.2019 Página 1 de 9 


\section{RESUMEN}

Objetivo: Analizar las vivencias de sufrimiento de los trabajadores de equipos de atención básica y las estrategias utilizadas en el desempeño de sus acciones para evitar la enfermedad en un contexto de tragedia. Métodos: Estudio exploratorio-descriptivo, con abordaje cualitativo. La recolección de datos ocurrió en los meses de julio y agosto de 2013, por medio de una entrevista semiestructurada, realizada como trabajadores de la salud. Los datos se analizaron a través del análisis de contenido. Resultados: Fue posible constatar la existencia de sufrimiento ante una situación ocurrida de forma abrupta y desestabilizadora que favorece el sufrimiento, en la cual los trabajadores se encontraban expuestos a los riesgos de enfermedad. Conclusión: Notamos la necesidad de apoyo organizacional, con acciones y políticas de gestión que puedan construir procesos favorables para la salud de los trabajadores. Es de destacar que a pesar de los sufrimientos derivados del contexto de la tragedia, los trabajadores se refieren a un fortalecimiento subjetivo, con la adquisición de una nueva mirada a la vida.

Palabras clave: Atención Primaria a la Salud, Salud del Trabajador, Reconstrucción Posdesastres.

\section{INTRODUÇÃO}

Na contemporaneidade, inúmeros estudos são realizados acerca de situações traumáticas decorrentes de tragédias, que causam sofrimento nas pessoas, desorganizando suas vidas de forma abrupta (PORTO MFS, 2016; THOME, 2012). Tais situações requerem maior compreensão, a fim de subsidiar o acompanhamento e a assistência necessários na tentativa de evitar o sofrimento psíquico (CANAVEZ F, 2012).

Em 27 de janeiro de 2013, a população de Santa Maria, município da região central do Estado do Rio Grande do Sul, sofreu o impacto de um evento extremo, um incêndio ocorrido em ambiente de entretenimento. Essa situação inesperada envolveu principalmente jovens universitários, atingindo a vida de inúmeras pessoas e culminando na necessidade da articulação de diversas ações públicas para atender às demandas oriundas do ocorrido (BORGES et al., 2019).

Considerando as demandas decorrentes deste evento, o município se organizou em frentes de trabalho, com destaque, às equipes de Atenção Básica $(A B)$ que possuíam, vítimas diretas e indiretamente envolvidas no cuidado a ser prestado. Estas equipes são referências aos usuários do sistema, sendo assim, a responsabilidade da construção de vínculos e cuidado longitudinal (BRASIL, 2004). Em situação de tragédia, o desempenho das ações inerentes é afetado, tanto pelo contexto de sofrimento destes usuários e trabalhadores, quanto pelo fato de que tal situação exige intervenções qualificadas e singulares, para as quais devem ter preparo e respaldo.

Habitualmente, a oferta de serviços na rede básica demonstra ser orientada por um modelo fragmentado, sem destaque efetivo à saúde do trabalhador, e assim, quando acionadas para responder de modo distinto, podem estas dificuldades ser potencializadoras de sofrimento às equipes (FERTONANI HP, et al., 2015).

Tais questionamentos justificam-se pela pertinência de compreender e identificar as vivências de sofrimento no trabalho em um contexto de tragédia, não somente para a ampliação do conhecimento científico, mas como contribuição para melhoria no processo de trabalho no período pós tragédia. O Termo de Compromisso celebrado entre União, Estado e Município, envolve um conjunto de ações para continuidade da atenção à saúde de vítimas, familiares e profissionais por um período mínimo de cinco anos de intervenção específica (FERTONANI HP, et al., 2015).

Considerando tais elementos, o referencial teórico utilizado é o da Psicodinâmica do Trabalho, que objetiva analisar as vivências de sofrimento, significados produzidos, sua relação com a organização do trabalho, compreender as estratégias utilizadas pelos trabalhadores para evitar o adoecimento (BAGALHO JO, 2017).

Assim, este estudo emerge dos seguintes questionamentos: Quais estratégias de defesa os trabalhadores utilizaram e qual o impacto no processo de trabalho? 
Dessa forma, para responder à questão norteadora a pesquisa tem como objetivo analisar as vivências de sofrimento dos trabalhadores de equipes de atenção básica e as estratégias utilizadas no desempenho de suas ações para evitar o adoecimento em um contexto de tragédia.

\section{MÉTODOS}

Trata-se de uma pesquisa exploratório-descritiva, com abordagem qualitativa de natureza compreensiva, constituído a partir de um recorte temporal do período entre fevereiro e agosto de 2013.

O cenário da pesquisa foi constituído por cinco serviços que compõem a rede de $A B$ do município de Santa Maria/RS, mais especificamente, cinco Estratégias de Saúde de Família (ESFs) que receberam apoio do Grupo de Trabalho Apoio à Atenção Básica e Redes (GTABR), no período pós-tragédia, entre os meses de fevereiro e agosto de 2013.

Como critérios de inclusão foram considerados: ser trabalhador de ESF da rede de AB no Município de Santa Maria onde ocorreram vítimas diretas e ser integrante de ESF que recebeu apoio do GTABR. Foram excluídos do estudo os trabalhadores que estavam em férias, laudo, atestado ou licença de qualquer natureza no período de coleta da pesquisa.

A coleta de dados foi realizada por meio de entrevista semiestruturada pela Assistente Social Residente da Residência Multidisciplinar em Saúde (RMS), por meio de questões abertas, nas quais o informante tem o direito de discorrer sobre suas experiências (BARDIN L, 2011). Para garantia do sigilo e anonimato, foram utilizadas letras maiúsculas: $E$ (enfermeiro), seguido da identificação numérica correspondente à ordem em que se realizou a coleta, exemplo, E1, E2 e assim por diante.

Foram efetuadas entrevistas com dez trabalhadores das cinco ESFs, sendo esse: dois médicos, 3 enfermeiras, 3 agentes comunitárias de saúde e 2 técnicas de enfermagem. A escolho dos profissionais deuse por sorteio e a escolha das ESFs ocorreu por essas recebem apoio da RMS.

No que tange à análise dos dados, as informações coletadas foram ordenadas, classificadas e analisadas segundo marcos referenciais construídos, agrupando conteúdos manifestos em grupos de sentido para dar suporte para a interpretação dos dados. Estes foram analisados por meio do método de Análise de Conteúdo (PALADINO E e TOMÉ JT, 2011). As fases da análise dividem-se em: pré-análise, exploração do material e tratamento dos resultados, inferência e a interpretação.

As entrevistas foram realizadas após o atendimento às exigências éticas e científicas, garantidas pela aprovação do Comitê de Ética em Pesquisa, número CAAE 18952813.1.0000.5346 da Universidade Federal de Santa Maria e pelo Termo de Consentimento Livre e Esclarecido (TCLE).

\section{RESULTADOS E DISCUSSÃO}

\section{O Sofrimento do Trabalhador em um Contexto de Tragédia}

Com a ocorrência de uma tragédia, os trabalhadores envolvidos tornam-se suscetíveis às mesmas consequências emocionais dos atingidos. É possível perceber em alguns o sentimento de impotência que pode acarretar em transtornos emocionais, fazendo-se necessária a busca por subsídios técnicos e teóricos para garantir suporte aos cuidadores (DEJOURS C, 1999).

Eu tenho impressão de que tudo vai pegar fogo. Acho que estou neurótica até, meu quarto não deixo mais fechado, não deixo nada ligado de noite, que eu deixava, tiro tudo das tomadas, com medo. (E5)

Nós estamos desesperados, todos estão sofrendo com isso; basta que dois se encontrem para começar [...] eu acho que esse sofrimento é geral, o que coloquei aqui de tristeza sobre essa tragédia é o que todos meus colegas que trabalham na saúde estão sentindo. (E1) 
Quando acontece uma tragédia do modo como aconteceu, de forma repentina, e tu profissional não estás preparado, tu te deparas com a obrigação de ajudar as pessoas. (E2)

O sofrimento mostrou-se decorrente tanto do evento em si, quanto por exigir respostas humanas organizadas, refletindo o grau de consciência dos trabalhadores acerca da complexidade da situação e da necessidade de trabalhá-la na maior abrangência de aspectos possíveis (PORTO MFS, 2016).

É importante compreender que o trabalho pode ser fonte de sofrimento, visto que se apresenta também como uma vivência de experiências dolorosas, como medo, angústia, insegurança, advindas de contradições e conflitos entre os desejos e as necessidades do trabalhador (DEJOURS C, 1999).

Em situações de tragédia este processo intensifica-se, o equilíbrio das pessoas envolvidas nessas condições adversas tende a ficar fragilizado. Para uma significativa parcela da população, a ordem psíquica poderá ficar comprometida por longos períodos (OLIVEIRA EC, et al., 2017).

A Psicodinâmica do Trabalho tem como premissa que o trabalho admite a construção da identidade do sujeito, dependendo do conteúdo da tarefa executada, do significado e da relação que o trabalhador estabelece com o trabalho. Os sintomas físicos e psicossociais aparecem devido às adversidades vivenciadas e do modo dos sujeitos lidarem com essa realidade (ZILIOTO DM e OLIVEIRA BO, 2015).

Sinto muita angústia, impotência principalmente, a impotência por não poder fazer algumas coisas e a angústia por isso, por saber que tem coisas que não pode fazer, que não tem condições. (E4)

Como profissional foi extremamente frustrante, porque me perguntava: e agora, o que é que eu faço com essa população? Como é que eu vou atender nas condições que eu tenho? Então está bem complicado... (E9)

A vivência do sofrimento mostrou-se não ser totalmente consciente, apresenta um aspecto inapreensível e indissociável da corporalidade. Percebe-se que o sofrimento é sempre um sofrimento do corpo, engajado no mundo e nas relações com os outros (DEJOURS C, 1999).

A tragédia foi de uma dimensão tão grande, e o que teve visibilidade foi o sofrimento das pessoas; o que não aparece, o que está nos bastidores é o sofrimento dos profissionais. (E2)

A tragédia não matou só aquelas pessoas que estavam lá, além de ter matado de certa forma os familiares, agrediu também os profissionais. Porque a imprudência, a falta de fiscalização, gerou toda esta tragédia e submeteu os profissionais a um sofrimento que eu considero sobre-humano. (E9)

Estes extratos permitem compreender que situações adversas extremas colocam à prova o equilíbrio psíquico de todos que foram expostos ao evento disruptivo, tanto a população afetada como os trabalhadores envolvidos, que podem se desestabilizar emocionalmente e adoecer ao vivenciar sentimentos de desamparo, podendo afetar a estabilidade psíquica de modo devastador (THOMÉ, 2012).

É importante compreender que em situações nas quais o trabalhador vivencia o sofrimento do outro, é possível se estabelecer uma situação desestabilizadora demandando que este seja flexível na busca de equilíbrio entre si mesmo e o seu contexto. Ocorrendo uma quebra abrupta desse equilíbrio, institui-se a crise que pode comprometer a saúde mental ou não (ALVES AP, et al., 2015; PARANHOS ME e WERLANG BG, 2015).

Entretanto, sendo esta crise resolvida de modo satisfatório, poderá ser um princípio para mudanças que contribuam para um melhor funcionamento do sujeito (LIMA M e DIMENSTEI M, 2016).

Eu não posso te dizer que não me afetou se eu estou reagindo assim. Mas eu acho que depois da Kiss eu consegui desenvolver uma coisa em mim que faltava ainda 
como profissional, eu acho que mais humano (choro) [...] eu era muito dura, muito exigente, muito dentro das regras e acho que eu pude voltar esse olhar mais humanizado. (E6)

Com a tragédia, penso em tentar melhorar, me aprimorar enquanto pessoa, para atender como profissional, para ter empatia suficiente para que a minha prática profissional seja efetiva. (E4)

O sofrimento é uma experiência vivenciada, é um estado mental que implica um movimento reflexivo sobre seu estar no mundo (DEJOURS C, 1999). Por meio das falas, é percebida a existência de sofrimento com relação à situação vivenciada, na qual os sentimentos de insegurança, desamparo e fragilidade emergiram nesse período, traduzindo grande exigência emocional.

\section{As estratégias defensivas empregadas para evitar o adoecimento}

Na abordagem da Psicodinâmica do Trabalho, o sofrimento pode ser enfrentado por meio de técnicas de mediação que tem por finalidade evitar conflitos psíquicos dos colaboradores. Esta concepção trata de estratégias defensivas, em uma relação não apenas individual, mas coletiva do trabalhador com a organização do trabalho (DEJOURS C, 2006). Nas estratégias coletivas existe um consenso do grupo em utilizá-las e há necessidade de condições externas criadas por esse grupo para que esta ocorra, na estratégia individual é constituída por mecanismos internos (MAISSIATA GS, et al., 2015).

A análise dos fragmentos revelou que as estratégias de defesa utilizadas no ambiente de trabalho, no sentido de enfrentar o sofrimento decorrente da tragédia, foram de caráter individual, constituídas por mecanismos internos, considerando que as defesas podem ser de proteção, de adaptação e de exploração (DEJOURS C, et al., 1993; GHIZONI LD, et al., 2014).

As estratégias de proteção caracterizam-se como maneira de pensar, de agir e sentir de forma compensatória, onde o trabalhador evita o sofrimento de modo alienado de suas causas, não buscando ações de mudança sobre a organização do trabalho.

Eu prefiro nem falar sabe, porque sei que seu eu falar vou desabar. É muito difícil. Mas a gente vai tentando levar da melhor maneira possível. Mas não quero chorar. Mas é difícil. (E5)

Eu criei personagens, e quando saía de uma situação difícil eu dizia: estou mudando o personagem, agora ele é alegre. É uma questão de tu proteger, porque estava muito ruim de trabalhar. (E10)

Evidenciam que esta estratégia de defesa faz com que o trabalhador evite o sofrimento de modo alienado de suas causas, não buscando ações de mudança sobre a organização do trabalho. Este modo de proteção, com o passar do tempo, poderá se esgotar fazendo com que ocorra maior precarização na organização do trabalho. Ao não enfrentar o sofrimento, o mesmo pode aumentar, possibilitando o surgimento do adoecimento ao trabalhador (LAVNCHICHA GRFS, 2015). Outra estratégia de defesa individual é a de adaptação, que tem como suporte a negação, mas a maneira de pensar, agir e sentir está mais focada na resignação e controle de suas emoções.

Eu acho que o que fiz foi parar de falar nisso, não sei se foi o melhor, mas parei de ver fotos de vítimas, de ver histórias de vítimas [...] a gente tem que deixar as feridas se curarem. (E6)

Acho que muitas coisas mudaram, é uma coisa que tu tens que se adaptar, uma nova fase, é complicado, me senti mais sozinha; então a gente tenta melhorar, mas é bem difícil (Choro). (E3)

$\mathrm{Na}$ estratégia de exploração, o trabalhador focaliza sua forma de pensar e agir frente ao sofrimento somente para contemplar ao desejo da produção do trabalho, desconsiderando os seus, negando com isso, seu sofrimento para manter-se em produtividade. 
O uso das estratégias constitui-se como uma forma do indivíduo buscar equilíbrio das vivências de prazer e sofrimento, visando uma relação mais favorável com o trabalho, fundamental para a construção da identidade do trabalhador no aspecto social e na luta contra o adoecimento (LAVNCHICHA GRFS,2015).

O estudo revela que a utilização somente de estratégias individuais poderá não ser suficiente para evitar sofrimento e adoecimento. Entende-se que a garantia da saúde não é de responsabilidade somente do indivíduo: a organização, o município, o Estado tem papel relevante no que tange ao cuidado à saúde do trabalhador.

Pode ser só um mecanismo de defesa não falar, não sei se ia gostar de falar, mas de alguma forma acho que suporte psicológico seria interessante. (E6)

Tem colegas com sérios problemas emocionais, tem dias que a gente pode contar com eles, tem outros que não e isso também envolve a gente, tem colegas que nem se falam. (E1)

Eu faço atividades de lazer; procuro fazer atividades físicas, mas procurar um atendimento psicológico eu nunca procurei (Choro). (E3)

Evidencia-se a necessidade de haver mobilização subjetiva ou coletiva para que o trabalhador consiga transformar as vivências de sofrimento e integrar-se em seu trabalho (GHIZONI LD, et al., 2014). Nessa lógica, o sujeito enfrenta o sofrimento ao ponto de entrar em sintonia com sua subjetividade, fazendo uso de sua inteligência prática e o trabalho em conjunto com os demais trabalhadores para transformar as situações que levaram ao sofrimento (LAVNCHICHA GRFS,2015).

Enfrentar uma situação limite pode ser momento de fortalecimento e fazer com que conceba a vida com outros olhos, o que muitas vezes proporciona aquisição de outros valores (NETO OD e BELO FRR, 2015). O sofrimento funcionará como força propulsora de ação no trabalho para a superação da condição limitadora, proporcionando a emancipação individual, o aprendizado e a experimentação da solidariedade (DEJOURS C, 1999).

O desenvolvimento de estratégias defensivas mostra-se como um modo de cuidado, e cuidar é uma atitude tanto individual quanto coletiva. Assim, abarca uma atitude de responsabilização, preocupação e envolvimento afetivo com o outro. O trabalhador de saúde, na condição de cuidador e necessitado de cuidado, está exposto a inúmeras tensões e possibilidades, que eventualmente são inesperados e difíceis de enfrentar (DEJOURS C, et al., 1994; BRASIL, 2004).

\section{A relação entre o modo de organização do trabalho e o sofrimento}

O sofrimento no contexto das organizações está associado à história singular de cada indivíduo e aos aspectos relacionados à atual situação, apresentando uma dimensão temporal que compreende processos construídos pelo próprio trabalhador no que se refere às suas atividades (LANCMAN S, 2008).

A organização do trabalho pode atuar como desestabilizador para a saúde mental dos trabalhadores, indicando a diferença entre a organização e as condições do trabalho. A organização do trabalho influencia o funcionamento psíquico, diz respeito aos conteúdos simbólicos e materiais do significado das tarefas. Já as condições de trabalho referem-se ao caráter ergonômico das atividades, as atividades físicas, químicas, biológicas e influenciam basicamente o corpo e a saúde física dos indivíduos (LANCMAN S, 2008).

Nós, trabalhadores, estamos em permanente processo de adoecimento, em função da falta de condições de trabalho, das cobranças. Precisou acontecer uma tragédia como esta para as pessoas verem que a rede está ruim; quantos pacientes a gente tem que falecem por falta de atendimento, por falta de condições...(E4)

A gestão tinha que estar mais presente na unidade, para ver a realidade, ver como realmente está funcionando, o que não está funcionando e porquê. Nesse sentido a gente está bem desamparado. (E1) 
O indivíduo sente necessidade emocional de respaldar a sua vida pessoal, familiar e profissional em uma rotina planejada, segura e que equipare aos outros seres humanos de sua convivência. Quando esse indivíduo não vivencia a segurança que a organização deve oferecer, ocorre o sofrimento (OLIVEIRA EC, et al., 2017). As tragédias potencializam efeitos da fragilidade da organização e modos de trabalho, exigem que os trabalhadores ampliem seu campo de atuação frente às novas necessidades, que abrange o campo do saber e fazer da saúde mental, já que estes eventos imprevisíveis atingem populações em sua maioria são, desorganizando seu habitual modo de viver.

Nós tivemos que sair da zona de conforto que a gente estava, de não dar tanta importância para a saúde mental e de repente se voltar para famílias que estavam tendo uma necessidade muito grande de apoio. (E6)

Suporte a gente não recebeu. E a gente teve dificuldades porque queríamos fazer visita para as famílias e ver como estava a situação e a gente não conseguia transporte. (E6)

Compreende-se que este movimento em busca de novos saberes para subsidiar os novos modos de intervenção foi disparador das vivências de sofrimento entre os trabalhadores, que experimentaram custos emocionais, colocando-se em destaque a ausência de suporte organizacional. $O$ trabalhador não realiza somente atividades laborais, suas vivências se dão no local de trabalho e além deste. Nesse sentido, suas experiências no trabalho influenciam sua vida, podendo impactar no núcleo familiar (GIONGO CR, et al., 2015; CARDOSO ACM, 2015).

Viabilizar espaços de discussão coletiva é fundamental para diminuir o sofrimento, atribuindo autonomia aos trabalhadores. As organizações do trabalho deveriam propiciar convivência, possibilitando o bem viver em sociedade que se referem ao aspecto social do trabalho, permitindo uma subjetividade saudável entre os membros da equipe. Esta constitui a matéria prima de toda e qualquer produção e é desenvolvida por meio da interação com o outro, nas relações sociais.

A tragédia foi um somatório, a equipe tem um histórico complicado, então não é coisa de agora, de um ano ou de dois, temos problemas desde que se criou a unidade. (E4)

O momento da tragédia foi complicado, porque ninguém estava preparado. A gente tinha que lidar com a situação de enfrentamento não só daquelas pessoas que precisavam da tua ajuda, mas também com os problemas da equipe. (E3)

O espaço de discussão deve ser utilizado pelo trabalhador na construção de argumentos não somente técnicos, mas abordando pontos de vista diferentes, crenças, desejos e valores. Inúmeras experiências de campo indicam que trabalhadores desejam expressar-se em espaço próprio e direcionados para subsidiar as discussões qualificadas (DEJOURS C, 1999).

Se existem pessoas que podem nos ajudar, que tenham um conhecimento maior do sofrimento humano, como [...] têm dentro da saúde mental, era importante que a gente pudesse conversar. Porque a gente precisa muito falar desse sofrimento. (E1)

Eu gostaria que a gestão tivesse tido a preocupação de encaminhar profissionais nem que fosse para participar da nossa reunião de equipe, porque este tema específico é um tema muito doloroso. (Choro). (E2)

O caráter clínico da abordagem psicodinâmica sugere mais que a observação, mas uma escuta voltada para o trabalhador e as relações subjetivas não evidenciadas, que precisam ser descobertas. $O$ trabalho passa ser compreendido não apenas por meio do invisível ou mensurável, mas por suas relações. A escuta viabiliza um espaço de reflexão ao trabalhador e a mobilização entre os sujeitos; este deve tornar-se capaz de apropriar-se do seu trabalho, mobilizando-se e favorecendo as mudanças para torná-lo mais saudável (RIBEIRO LR e SANTANA LC, 2015; ANTUNES R e PRAUN L, 2015). 
É importante salientar que a escuta oportuniza a reelaboração do sofrimento, que leva o trabalhador a readquirir sua capacidade de pensar e de agir frente ao problema, resgatando sua emancipação mental. Permite a mobilização do coletivo de trabalho para que possa encontrar novas formas de cooperação na formação dos membros desse coletivo enquanto sujeitos, a fim de viabilizar mudanças na organização do trabalho (DEJOURS C, 2006; GHIZONI LD, et al., 2014).

\section{CONSIDERAÇÕES FINAIS}

Há ocorrência de sofrimento evidenciado pelo sentimento de impotência e desamparo por parte dos trabalhadores, que favorece riscos de adoecimento. Identificou-se que a organização do trabalho exerce influências significativas na saúde mental dos trabalhadores apresentando condições de trabalho desfavoráveis pela ausência de suporte organizacional, manifestado pela impotência, insegurança e fragilidade ao deparar-se com a vivência de uma experiência dolorosa. As estratégias de defesas retratadas foram de cunho individual. Não foram evidenciadas nos depoimentos o desenvolvimento de estratégias de mobilização coletiva, o que reforça a importância do investimento organizacional. Destaca-se que apesar dos sofrimentos advindos do contexto da tragédia, os trabalhadores referem um fortalecimento subjetivo, com aquisição de um novo olhar diante da vida.

\section{REFERÊNCIAS}

1. PORTO MFS. A tragédia da mineração e do desenvolvimento no Brasil: desafios para a saúde coletiva. Cad. Saúde Pública, Rio de Janeiro, 32(2), 2016.

2. CANAVEZ F. O trauma em tempos de vítimas. Ágora (Rio de Janeiro) v. XVIII n. 1 jan/jun 2015

3.THOMÉ. Página da web. 2012. Disponível em: http://www.josethome.med.br/index.php/licoes-em-saude-mental-2/

4. Brasil. Ministério da Saúde. Secretaria-Executiva. Núcleo Técnico da Política Nacional de Humanização. HumanizaSUS: Política Nacional de Humanização: a humanização como eixo norteador das práticas de atenção e gestão em todas as instâncias do SUS / Ministério da Saúde, Secretaria-Executiva, Núcleo Técnico da Política Nacional de Humanização. - Brasília: Ministério da Saúde, 2004.

5 FERTONANI HP, et al. Modelo assistencial em saúde: conceitos e desafios para a atenção básica brasileira. Ciência \& Saúde Coletiva, 20(6):1869-1878, 2015.

6 BAGALHO JO. A organização do trabalho prisional e as vivências de prazer e sofrimento. Estudos de Psicologia, 22(3)305-315, 2017.

7. MINISTÉRIO DA SAÚDE. Termo de Compromisso Ministério da Saúde, Secretaria do Estado do RS, Secretaria Municipal de Saúde de Porto Alegre, Secretarias de Saúde e Gestão do Município de Santa Maria e a Universidade Federal de Santa Maria, 2013.

8. MINAYO MCS, et al. O desafio do conhecimento: pesquisa qualitativa em saúde. São Paulo: Hucitec, 2010.

9. GIL AC. Como elaborar projetos de pesquisa, 4 ed. São Paulo: Atlas, 2009.

10. BARDIN L. Análise de conteúdo. 5. ed., 2011.

11. PALADINO E, THOMÉ JT. Psicologia em tempos de tragédia. In: Revista Mente e Cérebro, ed. 221 - junho de 2011.

12. DEJOURS C. Conferências brasileiras: identidade, reconhecimento e transgressão no trabalho. São Paulo: FUNDAP, 1999.

13. OLIVEIRA EC, et al. O cuidado em saúde mental no território: concepções de profissionais da atenção básica. Esc Anna Nery 2017.

14. ZILIOTO DM, OLIVEIRA BO. A organização do trabalho em call centers:implicações na saúde mental dos operadores. Rev. Psicol., Organ. Trab. vol.14 no.2 Florianópolis jun. 2014

15. ALVES AP, et al. Prevalência de transtornos mentais comuns entre profissionais de saúde. Rev enferm UERJ, Rio de Janeiro, 2015

16. PARANHOS ME, WERLANG BG. Psicologia nas emergências: uma Nova prática a ser discutida. Psicologia: Ciência e Profissão, ISSN 1414-9893, ISSN-e 1982-3703, Vol. 35, №. 2, 2015.

17.LIMA M, DIMENSTEI M. O apoio matricial em saúde mental: uma ferramenta apoiadora da atenção à crise. Interface (Botucatu). 2016.

18. DEJOURS C. A banalização da injustiça social. Tradução Luiz Alberto Monjardim. 7. Ed. São Paulo: FGV. 2006.

19. MAISSIATA GS, et al. Contexto de trabalho, prazer e sofrimento na atenção básica em saúde. Rev Gaúcha Enferm. 2015 
20. DEJOURS C, et al. Por um trabalho, fator de equilíbrio. Revista de Administração de Empresas, São Paulo, v.33, n. 3, p. 98-104, maio-jun, 1993.

21. GHIZONI LD, et al. Clínica Psicodinâmica do Trabalho: a prática em diversos contextos de trabalho. DESAFIOS: Revista Interdisciplinar da Universidade Federal do Tocantins V. 1, n. 1, p. 74-94, jul/dez. 2014.

22. LAVNCHICHA GRFS. A clínica psicodinâmica do trabalho: teoria e método. KHÓRA, REVISTA TRANSDISCIPLINAR, V. 2, N. 2, MAIO 2015.

23. NETO OD, BELO FRR. Psicologia das emergências. Revista Interinstitucional de Psicologia, 8 (2), Edição Especial, dezembro, 2015,

24. DEJOURS C, et al. Psicodinâmica do Trabalho: Contribuição da Escola Dejouriana à análise da relação prazer, sofrimento e trabalho. São Paulo: Atlas, 1994.

25. LANCMAN S. O mundo do trabalho e a psicodinâmica do trabalho. In: LANCMAN S, SZNELWAR LI (Orgs.). Christophe Dejours: Da psicopatologia à psicodinâmica do trabalho. Rio de Janeiro: Fiocruz; Brasília: Paralelo 15, 2008.

26. GIONGO CR, et al. Psicodinâmica do Trabalho no Brasil: Revisão Sistemática da Literatura. Trends in Psychology / Temas em Psicologia - 2015.

27. CARDOSO ACM. O trabalho como determinante do processo saúde doença. Social, revista de sociologia da USP,2015.

28. RIBEIRO LR, SANTANA LC. Qualidade de vida no trabalho: fator decisivo para o sucesso organizacional. Revista de Iniciação Científica - RIC Cairu. Jun. 2015.

29. ANTUNES R, PRAUN L. A sociedade dos adoecimentos no trabalho Serv. Soc. Soc., São Paulo, n. 123, p. 407-427, jul./set. 2015.

30. BORGES MJ et al. Boate Kiss e a ressignificação do cotidiano de uma sobrevivente. CADERNOS DE COMUNICAÇÃO (UFSM), v. 1, p. 56-75, 2019. 